\section{Sleights of mind}

\section{What the neuroscience of magic reveals about our everyday deceptions}

\author{
Stephen L. Macknik and Susana Martinez-Conde; with Sandra Blakeslee \\ Henry Holt and Company. New York, New York, USA. 2010. \\ 304 pp. \$26.00. ISBN: 978-0-8050-9281-3 (hardcover).
}

Reviewed by Gustav Kuhn

Brunel University, Uxbridge, West London, United Kingdom. E-mail: Gustav.Kuhn@brunel.ac.uk

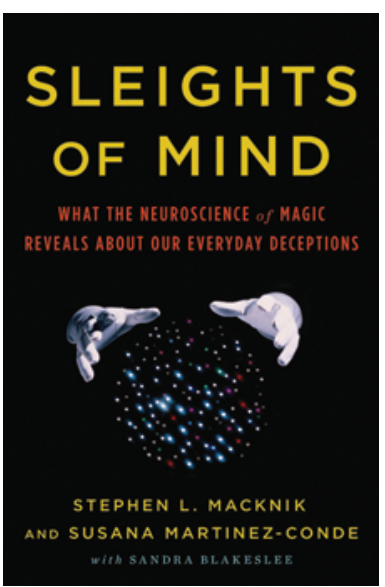

$\mathrm{H}$ ave you ever wondered how magicians are able to make things disappear in front of your eyes? It may come as little surprise to the readers of this journal that these feats are carried out without supernatural powers. Instead, magicians use a wide range of powerful psychological techniques to manipulate perception and awareness. Sleights of Mind: What the Neuroscience of Magic Reveals about Our Everyday Deceptions is written by Stephen Macknik and Susana Martinez-Conde, two well-established neuroscientists working at the Barrow Neurological Institute in Phoenix. Over the last three years, they have formed links with renowned magicians and have tried to explain magic tricks in terms of psychological and neurobiological processes. In this book, the authors describe their journey into the secretive world of magic. By describing some of the magicians' techniques and revealing many (perhaps too many) of their secrets, the authors try to explain some of the psychological and neurobiological processes involved in everyday cognition.

Sleights of Mind was preceded by journal publications in which the authors explored some of the links between magic and neuroscience (1). Their thesis is that scientists can learn much from magicians and that doing so may advance neuroscience by decades. Sleights of Mind is an extension of this, and in the book they declare themselves the founders of a new discipline they call neuromagic. This is a surprise, given that the authors, who head two large neuroscience research groups, have in fact not published any empirical work that has been inspired by magic. This presents the central flaw with this text: although the term neuromagic may be new, the authors' claims of having founded this field of science do not reflect their own level of research in this area or pay due recognition to the established body of work that precedes this book (2).
That said, the general topic of magic and neuroscience will be of interest to a fairly wide readership. The main substance of the book is based on interviews with some of the world's most renowned magicians, who offer great insights into their rather secretive world. While some magicians will be perturbed by the way in which many well-kept secrets are revealed, the depths and details of these methods will provide an easy thrill for the nonmagician. For example, professional pickpocket Apollo Robbins offers intriguing insights into how he misdirects his marks' attention in order to steal their possessions. Similarly, Teller describes one of the classics in magic, the "Miser's Dream," in which the magician plucks countless coins out of thin air and illustrates how magicians manipulate your assumptions about the world. Most of the examples are then followed by descriptions of everyday cognitive processes. The authors use the principle of misdirection to describe the way in which the visual system systematically selects the relevant information, resulting in a rather impoverished representation of the world, which leaves much scope for deception. While the book is valuable for its descriptions, many of the conclusions seem rather speculative and are rarely backed up by scientific evidence.

The authors have immersed themselves in the world of magic and should be commended for their collaborations with eminent and insightful magicians. While the authors place themselves at the front of a "new" scientific field, they neglect both past and current research concerning the scientific study of magic. They fail to acknowledge that scientists as far back as the 1900s have explored the psychological mechanisms involved in conjuring (3). In addition, many of the concepts covered by this book are psychological rather than neurobiologi- cal, and the neuroscience used to describe magic often feels imposed. Given that the authors are active scientists, it is also perplexing that numerous recent scientific findings have been missed. For example, in the chapter on misdirection, the authors talk about how magicians use social cues (e.g., where they are looking) to misdirect people's attention, but fail to mention research that has already investigated these issues (4). Similarly, they raise the possibility that individuals with autism who have difficulties in processing social information may be less readily misdirected and therefore more likely to detect the magician's secret, without discussing work that has investigated these questions (5).

Sleights of Mind offers interesting insights into the tricks and techniques used by magicians that will be of interest to many readers. Moreover, the use of magic as a vehicle to describe cognitive and neurological processes generally works well. However, I was disappointed by the presumptuous and unsubstantiated accounts and claims within the book. As the authors fail to propose a clear framework for their idea of a new "neuromagic" and do not present any of their own neuroscientific contributions to the field, this book should be taken as a personal account rather than the birth of a new scientific discipline.

1. Macknik SL, et al. Attention and awareness in stage magic: turning tricks into research. Nat Rev Neurosci. 2008;9(11):871-879.

2. Kuhn G, Amlani AA, Rensink RA. Towards a science of magic. Trends Cogn Sci. 2008;12(9):349-354.

3. Triplett N. The psychology of conjuring deceptions. Am J Psychol. 1900;11:439-510.

4. Kuhn G, Tatler BW, Cole GG. You look where I look! Effect of gaze cues on overt and covert attention in misdirection. Visual Cognition. 2009;17(6-7):925-944.

5. Kuhn G, Kourkoulou A, Leekam SR. How magic changes our expectations about autism. Psychol Sci. 2010;21(10):1487-1493. 